\title{
Development of Interlanguage Pragmatic Competence: Input- and Output-based Instruction in the Zone of Proximal Development
}

\author{
Majid Nemati \\ English Department, Faculty of Foreign Languages and Literatures, University of Tehran, Tehran, Iran \\ Ali Arabmofrad (Corresponding author) \\ Faculty of Foreign Languages and Literatures, University of Tehran, Iran
}

\begin{abstract}
Among the Interlanguage Pragmatics (ILP) studies which have investigated the differential effect of different instructional treatments, little attention has been given to the role of the sociocultural concepts of Zone of Proximal Development (ZPD) and peer scaffolding in the development of pragmatic competence. Furthermore, none have juxtaposed the effect of incorporating an output-based instruction with an inputbased one. The study employed an experimental design over a 13 week period with 90 students randomly assigned to the one of the five groups consisting of four treatment groups and a control group. Each treatment group received one of the following kinds of instructions: (a) individual input-based, (b) collaborative inputbased, (c) individual output-based, or (d) collaborative output-based. Treatment groups' performance was compared with that of a control group on pretests and posttests consisting of a multiple choice discourse completion task and a written discourse completion task. The results indicated that there was a significant difference between pre- and posttests of the four experimental groups in both awareness and production. The results lend support to Schmidt's (1993) noticing hypothesis and Swain's (1985) output hypothesis and provides evidence for the success of Sharwood Smith's $(1991,1993)$ input enhancement techniques. However, the results cast doubt on the superiority of output based instruction over input based even in output focused activities. Further results and implications are discussed in the paper.
\end{abstract}

Index Terms-interlanguage pragmatics, zone of proximal development, peer scaffolding, input-based instruction, output-based instruction

\section{INTRODUCTION}

Interlanguage pragmatics (ILP), as a subfield of pragmatics and interlanguage studies, "uses pragmatic theories, principles and frameworks to examine how foreign/second language learners encode and decode meaning in their L2" (Schauer, 2009, p. 15). The findings of ILP studies on the learners' pragmatic development across different proficiency levels indicate that having high levels of grammatical competency will not necessarily guarantee comparable pragmatic competence (Bardovi-Harlig, 2001; Taguchi, 2007, 2009; Takahashi, 1996). That is, even grammatically advanced learners may convey the intended meaning and politeness values inappropriately, in a way that is different from native like performance and pragmatic norms (Eslami-Rasekh, 2005; Eslami-Rasekh, Eslami-Rasekh, \& Fatahi, 2004). Consequently, though it is very difficult to teach pragmatics in the L2 classroom (Kasper \& Schmidt, 1996), the teaching of pragmatics is of high importance especially in the foreign language context in which learners have limited opportunities to be exposed to the target language (Kasper, 2001a, 2001b; Kasper \& Rose, 2002).

The major models that have motivated many researches in ILP are Schmidt's (1993) noticing hypothesis, Sharwood Smith's $(1981,1993)$ consciousness raising model, later modified to Input Enhancement (IE), Swain's (1985, 1995, 1998) output hypothesis and more recently Vygotsky's (1978) Sociocultural Theory (SCT). While there is an abundance of studies that examine and support noticing hypothesis (Olshtain \& Cohen, 1990; Safont, 2005) and IE (Takimoto, 2006, 2007, 2008), just a handful of studies are based on Swain's (1985) output hypothesis in teaching language pragmatics (e.g., Jernigan, 2007, 2012). Vygotsky's SCT is the next theoretical point of view that has been barely applied in the realm of ILP. A quick review of the literature shows that just a few observational studies informed by SCT touch on pragmatics in some way (Donato, 1994; Ohta, 1999, 2001). But none of these studies looks at the role of the ZPD and peer scaffolding in the development of pragmatic knowledge. In addition, the findings of such observational case studies are not generalizable to foreign language classroom contexts (Ohta, 2005). To date, only a very small number of studies have examined the role of the ZPD in ILP (e.g., Khatib \& Ahmadi Safa, 2011; Jabbarpoor \& Tajeddin, 2013).

Therefore the aim of the present study is to see the effectiveness of instruction in teaching pragmatics not only from a cognitive point of view (input vs. output-based) but also from a sociocultural point of view. More specifically, the 
present study seeks to clarify the possible role of ZPD and peer scaffolding in the development (i.e., awareness and production) of L2 pragmatic competence.

\section{LITERATURE REVIEW}

\section{A. Input Enhancement and ILP}

The most compelling evidence that instruction in L2 pragmatics or acquisitional pragmatics (Bardovi-Harlig, 2013) is necessary comes from advanced learners, with high levels of grammatical competency, whose communication frequently contain pragmatic errors (Mirzaei \& Esmaeili, 2013). Research findings of L2 studies that examined the teachability of pragmatic features suggest the necessity and effectiveness of instruction (Bardovi-Harlig \& Hartford, 1993; Rose, 2005). "The two specific pedagogical approaches to draw the learner's attention to form [...] are visual (textual or typographical) input enhancement and the learners' output" (Izumi, 2002, p.543). To promote learning, the learner should pay attention to forms, functions and contextual features but due to the non-saliency and infrequency of some forms, there should be a focused attention to learning (Schmidt, 1993, 1995, 2001). In this regard, Sharwood Smith $(1991,1993)$ suggests Input Enhancement (IE) techniques (e.g. stress in speech or boldfacing in printed text) by which language input becomes salient to the learner.

A bunch of studies have provided empirical evidence supporting IE techniques (e.g. Takahashi, 2001; Takimoto, 2006, 2007, 2008, 2009). Takahashi (2001) broadened the notion of IE, devising different input conditions which differed in their degrees of IE, namely, explicit teaching, form comparison and form search. In explicit teaching group, teacher-fronted metapragmatic information on the form function relationship (of target request strategies) was provided. In form-comparison condition, learners were required to compare their own request strategies with those of native speakers in similar situations and in form search condition, they were asked to find any native (like) usage in the input. The findings indicated that while learners in both implicit (form-search, form-comparison and meaning-focused) and explicit groups noticed the target request form and used them in the posttest, the learners in the explicit group outperformed those in the implicit one. Takimoto (2009) study evaluated the relative effectiveness of three types of input-based instruction: comprehension-based instruction, structured input instruction, and consciousness raising instruction. Four types of testing instruments were used in pre-, post-, and follow-up test; a planned role-play test, a planned discourse completion test, a planned acceptability judgment test and an unplanned listening judgment test. The results indicated that, while the testing method had an effect on the participants' performance, three types of input-based instruction performed considerably better than the control group.

\section{B. The Output Hypothesis and ILP}

As mentioned above, learners' output is a specific pedagogical approach to draw the learner's attention to form. The output hypothesis claims that "the act of producing language (speaking or writing) constitutes, under certain circumstances, part of the process of second language learning" (Swain, 2005, p. 471). That is, output is both the result and contributor of acquisition because production makes the learner notice the gap (Izumi, 2002). While studies on the effects of output have grown in number and influence (e.g., Izumi, 2002, 2003; Nassaji \& Tian, 2010; Swain \& Lapkin, 2002), only a very small number of L2 studies have examined the role of output in ILP development (Jernigan, 2007, 2012).

Jernigan (2012), for instance, examined the effectiveness of output-based instruction. The participants were adult ESL learners with different first language backgrounds. The pretest and posttest consisted of a written discourse completion task (WDCT) and a pragmatic acceptability judgment task (PAJT). The results indicated that the instructional treatment had a significant effect on the PAJT. However, no significant effects were identified in the results of DCT, but the output group showed a relatively large effect size.

\section{Sociocultural Framework and ILP}

Vygotsky's (1978) Sociocultural Theory (SCT) of human learning describes learning as a social process and highlights teaching and learning in conjunction (Nassaji \& Cumming, 2000). The first central concept of the sociocultural theory is the Zone of proximal development (ZPD). It refers to the distance between what children can do and what they can do with the guidance from an a more skilled person. It highlights the progressive and step-by-step nature of learning stating that the child gets skills through interaction with a more skilled person. The second cardinal concept in sociocultural theory is scaffolding. Donato (1994) defined scaffolding as a "situation where a knowledgeable participant can create supportive conditions in which the novice can participate, and extend his or her current skills and knowledge to higher levels of competence" (p. 40). In language teaching and learning, scaffolding implies both the joint construction of language and the gradually withdrawing support of the teacher as the learner's competence develops, with the aim of making the learner ready to accomplish tasks independently.

While the sociocultural concepts of ZDP and scaffolding have been applied in language teaching and learning (Nassaji \& Cumming, 2000; Nassaji \& Swain, 2000; Nassaji \& Tian, 2010; Ohta, 1999, 2001; Storch, 2005), it has received scant attention in pragmatic development studies. Ohta (2005) considered the applicability of the ZPD to interlanguage pragmatics instruction, and analyzed three interlanguage pragmatics research studies through the framework of ZPD. She believed that although none of these studies have considered ZPD in their implementation and 
analysis, their study results could be explained from a ZDP perspective. She noted that in Yoshimi (2001, as cited in Ohta, 2005), for instance, the opportunities provided are the essence of the ZPD. The participants worked with some stories with the help of an expert who assisted them with instruction, revisions.

The dearth of research into the role of ZPD and scaffolding on developing interlanguage pragmatics has motivated only a very small number of studies so far. Khatib and Ahmadi Safa (2011), for instance, investigated the potentiality of role of the ZPD concept and different forms of scaffolding into the development of the foreign language learners' ILP competence. The participants were organized into three experimental and one control groups. While the subjects of the control group received ZPD-insensitive teacher scaffolding, the subjects in the experimental groups were given (either explicit or implicit) ZPD-wise scaffolding by the expert peers, or ZPD-insensitive scaffolding by their co-equals. The results revealed that the expert peers' ZPD-wise explicit and implicit scaffolding outperformed the other two intervention types for the subjects' co-construction of ZPD and ILP development and the co-equals' scaffolding proved to be the third effective procedure.

\section{THE PRESENT STUDY}

Theoretically motivated by cognitive and sociocultural frameworks mentioned above and based on the fact that, to date, a small number of studies have examined the application of ZPD and scaffolding on developing in L2 pragmatics, the present study is to investigate the role of ZPD and scaffolding in input- vs. output-based instruction. Input is operationalized as the ability of the input-based group to search for forms (form search) and compare them with what they would say in their first language (i.e., Persian) in a similar situation (form comparison). Output, on the other hand, is operationalized as the ability of the output-based group to answer WDCTs and to investigate the ZPD and scaffolding, the participants were divided into individual and collaborative groups. In collaborative groups, the expert peer assisted the other members. Consequently, the following research questions are investigated in the present study:

1. Do instruction type (input vs. output based instruction) and participants' grouping (individual vs. collaborative grouping) have any effect on the awareness of speech acts?

2. Do instruction type (input vs. output based instruction) and participants' grouping (individual vs. collaborative grouping) have any effect on the production of speech acts?

\section{A. Participants}

A total of 90 freshman Iranian EFL learners from Islamic Azad University of Gorgan, ranging from 18 to 20 years of age and studying English Literature and TEFL, took part in the main study. Among them 20 participants were upperintermediate (expert peers) and the rest were lower-intermediate. They constituted five classes and were randomly assigned to four treatment and one control groups. The original number of participants was 130. Twenty seven participants were excluded due to their marks in the placement test and 13 more were excluded from data analysis due to their absence in at least one treatment session. In addition, two American Native English Speakers took part in revising the researcher-made Written Discourse Completion Task (WDCT), and two American Native English Speakers rated the WDCT test.

\section{B. Instrumentation}

\section{Quick Placement Test}

A paper and pen version of the Quick Placement Test (QPT), developed by Cambridge ESOL and Oxford University Press, was used to ensure the homogeneity of the groups. The beginners and breakthroughs were excluded because, considering the participants' performance in the pilot study, at this level the learners had difficulty in writing and this low level of writing skill would affect their performance especially in WDCT. Since there should be_a more competent learner as the expert peer (in collaborative groups), 20 upper intermediate students were included in the five groups.

\section{Pretest and Posttest}

Developing L2 pragmatic competence was operationalized as learners' changes in performance on the two scales: (a 16-item) Multiple Choice Discourse Completion Test (MDCT) and (a 10-item) Written Discourse Completion Test (WDCT). For MDCT, 16 situations validated by Birjandi and Rezaei (2010) were modified and used. The 10 items developed for WDCT was done through examplar generation, likelihood investigation, metapragmatic assessment and piloting (see Jianda, 2007). For each speech act there were 5 and 8 scenarios in WDCT and MDCT respectively, which the participants completed in about two hours prior and subsequent to the experimental treatment in each of the five groups. Also the participants first took WDCT and then MDCT so as not to benefit from the items of MDCT.

\section{The WDCT Development and Validation}

Exemplar Generation. In order to approximate authentic situations the student encounter in their real life, 20 TEFL students of Azad University were asked to write either, in Persian or English, at least five situations in which they apologize, and ask (request something). In this way, a total of 200 situations were generated. A qualitative analysis of the situations showed that many of them were overlapping, thus 20 situations (10 situations for each speech act) were selected. 
Likelihood Investigation. To test the naturalness of the situations, thirty other students from the same pool were asked to rate the 20 selected situations from 1 to 5 on the basis of their frequency of occurrence and naturalness and the 10 scenarios with the highest mean scores were selected.

Metapragmatic Assessment. The 10 situations were balanced according to three sociolinguistic variables. This involved assessing the Imposition (the burden put on the hearer), social distance (the relationship between the interlocutors) and Power (the status of the speaker with respect to the hearer). An attempt was made to select those situations with different combinations of features. To approve the authenticity of the described situations for the realization of the intended speech acts, two NSs read and revised the WDCT test items.

\section{Treatment Materials}

The treatment materials were 24 native speakers' dialogue extracts adopted from ESL podcasts and tailored to the level of the participants by paraphrasing or deleting some difficult vocabularies, idioms and expressions. The number of prompts for each speech act was 12 covering various situations such as work, school, and home. To select each prompt, besides formality, sociopragmatic issues such as setting, imposition and power relations were taken into account.

\section{Pilot Study}

The pilot study involving 20 university students from the same pool as the main study was conducted three months before the main study. The participants were asked to answer a 16-item MDCT and a 10-item WDCT. Based on the results of this pilot study, some changes were made in the test items and also the procedure of the experiments. The items which had the lower correlation with the total scores were revised. The results indicated that the MDCT and WDCT scales were reliable at .78 for and .85 .

\section{Procedure}

The study was done as an integrated part of the "Conversation I" course of the BA level. First, the Oxford Quick Placement Test was given to the participants in each of the five classes to ensure the homogeneity of the participants by including lower intermediate and upper-intermediate. Then the participants were given the pretest, first they took WDCT and then MDCT. Having administered the pretest to five groups, the researcher provided them with the designed instructional approach. The control group was exposed to the same material as the four experimental groups without any pragmatics-focused instruction. The dialogue extracts of each speech act was presented in four hours (four consecutive sessions of 60 minutes), therefore, the whole instructional treatment lasted for 8 such sessions. In addition to the eight treatment sessions, five sessions were devoted to the introduction to course, administration of placement, pre and post tests. The first step for all the five groups was the presentation of the scenarios (dialogues) regarding speech acts. Following the presentation of the material, the control and experimental groups underwent the following procedures:

\section{The individual and collaborative input-based groups (IIG \& CIG)}

The participants in input groups received two types of materials: an instruction sheet and 24 native speakers' dialogue extracts. Having received and read the instruction sheet, the participants were presented with the transcripts of dialogues containing the focused speech act. In each session three dialogues were studied and each speech act was covered in four consecutive sessions. While they were not required to produce output, they were required to find and underline the different elements of the speech act under study (form search) on the basis of the short explanation of the instructor at the beginning of the session. Then, in both input-based groups, the participants compared what they would say in their first language (i.e., Persian) in a similar situation (form comparison). There was no interaction among participants in the classroom and it was only the teacher who selectively provided feedback when needed.

The participants of the collaborative group, on the other hand, worked in groups of four and five in which there were constant interaction and feedback on the part of members. The teacher assigned an upper intermediate member as the expert peer whose role was to scaffold other members. Before starting the treatment, to ensure that the expert peers knew how they were going to scaffold other members of the group, the teacher held two extra practice sessions with expert peers. To operationalize scaffolding strategies and to avoid over and under assistance by peer experts, Aljaafreh and Lantolf's (1994) regulatory scale which starts with the most implicit (level 0) and ends up with the most explicit instruction and feedback strategies (level 12) was applied. In the case there was a problem, the leader could get help from the teacher. The teacher constantly monitored the groups to ensure the interaction and feedback among the members. Just like the IIG, the participants of CIG didn't produce any speech acts.

\section{The individual and collaborative output-based group (IOG \& COG)}

The IOG and also COG participants received two types of materials: an instruction sheet and 24 native speakers' dialogue extracts. The participants of the output groups received the same materials as the input ones except that the 24 native speakers' dialogue extracts of the output based groups were followed by the description of the similar situation, having the same situational features as the dialogue, in which they were going to write what they would say in that situation. While the IOG participants were presented with the same dialogue extracts and then they were required to answer the WDCT individually, the participants of COG worked in groups of four and five to answer similar discourse completion tasks. The expert peer, following the Aljaafreh and Lantolf's (1994) regulatory scale, scaffolded the other members of the group.

\section{The control group $(C G)$}


The participants read the same dialogues and then they were asked to answer comprehension questions. That is, the focus was merely on meaning and activities following the presentation of the input didn't address pragmatic issues.

\section{RESULTS}

\section{A. Reliability of Scales}

To check the internal consistency of the MDCT, Cronbach's alpha coefficient of pretests and posttest was calculated and it was found that the reliability index exceeded 0.7 in both pre and posttest (.79 and .83 respectively). To check the reliability of the WDCT, first, internal consistency of pre- and posttest were calculated. The results showed the reliability of WDCT to be higher than that of MDCT and in both pre- and posttest: the scale enjoyed the Cronbach's alpha of .94 and .95 respectively.

With regard to the interrater reliability, first, two NS were trained in two sessions and they were asked to rate WDCTs on the basis of Jernigan's (2007) four point scale in which scores of 1 or 2 is indicative of a generally unacceptable or unacceptable response while a score of 3 or 4 indicate that the response is generally acceptable or completely acceptable. Therefore, there is a noticeable contrast in the scoring levels between the scores of 2 and 3; while a score of three is generally appropriate, a score of two is generally unacceptable. Then, to check the internal consistency of each scoring, the raters' Cronbach's alpha values of each of the raters were calculated and it was found that they were reasonably high at .83 and .81 . Then, the correlation of the rater's scores was examined as a way to estimate the interrater reliability. The results showed that there was a strong, positive correlation between the ratings of two raters $[\mathrm{r}=.82, \mathrm{n}=90, \mathrm{p}<.05]$.

\section{B. The First Research Question}

The first research question was to explore the possible effect of instruction and grouping on the learners' awareness (perception) of speech acts. To check for this effect, an MDCT was used. Based on the native speakers' answers in similar situations, a correct answer was awarded a score of 1 and a wrong answer 0 . The maximum possible score was 16. Table 1 presents a general overview of the trends of the MDCT in the pre- and posttests.

TABLE 1

DESCRIPTIVE STATISTICS FOR MDCT

\begin{tabular}{lllllll}
\hline & & Input based & \multicolumn{3}{c}{ Output based } & Control \\
& & Individual & collaborative & individual & collaborative & \\
\hline Pretest & Mean & 20.5 & 25.64 & 19.79 & 22.32 & 17.79 \\
& SD & 5.403 & 4.431 & 5.056 & 4.485 & 5.432 \\
posttest & Mean & 24.64 & 27.07 & 22.25 & 23.58 & 18.26 \\
& SD & 4.986 & 4.411 & 5.252 & 4.414 & 5.576 \\
$\mathrm{~N}$ & & 14 & 14 & 24 & 19 & 19 \\
\hline
\end{tabular}

As depicted in Table 1, it seems that, among the four treatment groups, there is an increase in the score means from the pretest to the posttest. The highest difference (gain score) in the mean is in IIG $(24.64-20.5=4.14)$ and the lowest difference is in COG $(23.58-22.32=1.26)$. Also, a glance at the mean differences of input and output-based groups indicates that the input group outperformed the output group.

To further analyze the data, a mixed between-within subjects ANOVA was conducted. The results showed a main effect for grouping $F(1,85)=6.735, \mathrm{p}=.011$; a main effect for instruction type $\mathrm{F}(1,85)=5.07, \mathrm{p}=.027$; and a main effect for time interval $\mathrm{F}(1,85)=14.756, \mathrm{p}=.000$ with a benefit for posttests. As for the interactions, none of the interactions turned out to be significant. Post-hoc comparisons for the five groups showed that there was significant difference between the individual and collaborative grouping and both were significantly better than the control group. As for the instruction type, post-hoc comparisons showed that the input group is significantly better than the output group, and both are significantly better than the control group. Post-hoc comparisons also indicated the following contrasts $(\mathrm{p}<.05)$ : the IIG, COG, CIG, and IOG groups performed significantly better than the control group and among the four experimental groups, CIG outperformed IIG, IOG, and COG. The two collaborative groups outperformed their individual counterparts. There are no statistically significant differences among the IIG, IOG and COG.

\section{The Second Research Question}

The second research question concerned the effect of instruction and grouping on the production of speech acts as measured via the WDCT. As can be seen in the Table 2, the collaborative output based group has the highest mean difference among the five groups and collaborative input based group has the lowest gain score. 
TABLE 2

DESCRIPTIVE STATISTICS FOR WDCT

\begin{tabular}{lllllll}
\hline & & Input based & \multicolumn{3}{c}{ Output based } & Control \\
& & Individual & collaborative & individual & collaborative & \\
\hline Pretest & Mean & 28 & 53.57 & 35.54 & 40.37 & 41.68 \\
& SD & 14.191 & 7.683 & 8.832 & 10.101 & 12.234 \\
posttest & Mean & 41.93 & 63.79 & 49.08 & 58.32 & 38.74 \\
& SD & 7.184 & 5.381 & 7.824 & 10.398 & 10.759 \\
$\mathrm{~N}$ & & 14 & 14 & 24 & 16 & 19 \\
\hline
\end{tabular}

To further assess the impact of two different interventions (instruction and grouping) on participants' scores on the WDCT, a mixed between-within subjects ANOVA was conducted. The results showed no main effect for instruction type $\mathrm{F}(1,85)=.205, \mathrm{p}=.65$; a main effect for grouping $\mathrm{F}(1,85)=49.000, \mathrm{p}=.000(\mathrm{p}<.0005)$; and a main effect for time interval $\mathrm{F}(1,85)=120.45, \mathrm{p}=.000$, with four groups showing an increase in MDCT scores across the two time periods. As for the interactions, there was a significant interaction between grouping and time, $\mathrm{F}(1,85)=4.85, \mathrm{p}=.04$ and a significant interaction between instruction and time, $F(1,85)=.80, p=.02$. There was also a significant interaction between Instruction and grouping, $\mathrm{F}(1,85)=49.00, \mathrm{p}=.000$.

Post-hoc comparisons for the five groups showed that the collaborative group outperformed both individual and control group and there was no significant difference between individual and control group. As for the instruction type, post-hoc comparisons showed no significant difference between input and output group, and both were significantly better than the control group. In addition, Post-hoc comparisons revealed the following contrasts ( $p<.05)$ : CIG perform significantly better than IIG, IOG, COG and CG. COG outperformed IIG and IOG and as in MDCT, the two collaborative groups outperformed their individual counterparts. However, there was no statistically significant difference between individual groups (IIG and IOG) and CG.

\section{DisCUSSION AND CONCLUSION}

The purpose of the present study was to investigate the differential effects of instruction and grouping on the awareness and production of speech acts. More specifically, the present study examined whether expert peers' scaffolding through output and input instruction promote noticing and learning of pragmatic features. The first research question concerned the effect of instruction and grouping on the participants' awareness of speech acts measured by MDCT. The results indicated that the input based groups performed significantly better than the control group. This is consistent with Takimoto $(2007,2008,2009)$ in which input based groups outperformed the control group. In addition, the results support noticing hypothesis and provide evidence for the success of input enhancement techniques showing that the pedagogical intervention had made specific target features of the input more salient and directed the learners' attention to these features and resulted in the increased depth of processing of speech acts.

Furthermore, the output-based groups significantly outperformed the control group which is in harmony with Izumi's (2002) and Jernigan's (2007) finding in which +output instruction improved the participants' awareness more than output instruction. This supports theoretical claims of the output hypothesis (Swain, 1985, 1995). The output produced by the learners, as Swain (1995) proposed, can help them notice their area difficulty that makes them search their own developing interlanguage system.

The CIG outperformed the two output-based groups (IOG \& COG) confirming the claims made by Ellis (1997) and VanPatten and Cadierno (1993) who proposed "that it is the manipulation of input (how learners perceive and process input) rather than output (how learners produce language output) that is more likely to result in the integration of intake into learners' implicit/declarative knowledge".

The results also showed that the two collaborative groups outperformed their individual counterparts in the awareness of speech acts. That is, collaborative pair work facilitated learners' attention to the target forms and learners who carried out the input and output tasks collaboratively were more successful. This is harmonious with those obtained by Khatib and Ahmadi Safa (2011) in which the expert peers' ZPD-wise explicit and implicit scaffolding were more effective than the other two intervention types for the ILP development.

The second research question explored the potential effects of instruction and grouping on the production of speech acts measured by WDCT. The results indicated that in spite of the observable mean increases from pretest to posttest in the output-based groups (comparing to those of the input-based groups), the output-based groups didn't outperform the input-based group in the WDCT. This may have more than one possible reason. First, because two speech acts are involved, they may need more time than the eight weeks of instruction in production oriented activities and as Jernigan (2012, p. 8) suggests, there may be the need "for more perception-focused activities early in learners' development, with more output-focused tasks integrated as learners advance". The second reason is related to "the number of scores which may have been too low for the analysis of variance (ANOVA) to identify the significant effects and interactions suggested by the trends in the raw data and effect size measures" (Jernigan, 2007, p. 124).

The fact that the IIG groups didn't outpace the CG where production was concerned is in line with skill based learning asserting that "a particular skill is learned as a result of practice". The skill based learning is contrasted to 'information-processing theory which claims that input-based instruction will serve to develop the participants' ability 
to comprehend and produce the target features drawing on the same underlying knowledge source" (Takimoto, 2009, p. 1041).

With regard to role of peer scaffolding, the collaborative groups showed significantly greater gains than their individual counterparts in the production of speech acts, showing the an advantage of collaborative pair work over individual work. With regard to the effects of pair work, the results of the study confirmed the results of ESL studies that have shown that engagement in collaborative activities may improve the learners' accurate production of the target forms (Swain, 1998; Lapkin \& Swain, 2000). However, the findings do not support the findings of ESL studies (e.g., Nassaji \& Tian, 2010; Storch, 1997, 2005) in which collaborative pair work did not lead to superior learning of targeted forms in comparison to individual work. This indicates that the context (ESL vs. EFL) might have a potential role in implementing ZPD and scaffolding. However, more research is needed to examine the application of SCT for learning pragmatic features in an EFL context.

Of the interesting results of WDCT analysis was that the CIG outperformed the COG even in the production of speech acts. This may have more than one possible reason: The first reason may be related to the fact that the same amount of time was allotted to both collaborative groups. Due to the interactions and the written task involved there may be the need to give more time to the collaborative output-based group. The second reason may be related to the nature of the interaction. Although the researcher constantly monitored the groups, as indicated by some of the participants, in some cases the interactions were, brief, and limited. This suggests that in future output-based studies learners' interaction must be taken into account. An analysis of transcripts of the interactions may be of great help in this regard.

The main contribution of the present study to the existing research literature is that it adopts a more comprehensive look towards the effect of instruction on developing pragmatic competence in EFL context. Taking into account the notion of ZPD and peer scaffolding in the implementation and analysis of the study, the present study juxtaposed the effect of incorporating learner output, whether individual or collaborative with the other cognitively oriented approach, that is, input enhancement. The findings of this study can have some pedagogical implications for the language teachers and learners in an EFL context. Due to the lack of adequate materials and training and a lack of emphasis on pragmatic issues in EFL courses, the pedagogical implication then for teachers is that they should attempt to make students recognize the importance of the pragmalinguistic and sociopragmatic features which is rife throughout the language learning. This can be accomplished by providing learners with extended opportunities to receive contextualized, pragmatically appropriate input and produce output. An important implication of the present study is that peer scaffolding is relatively effective for EFL learners' ILP development. The other implication of the present study is that the constructs of pragmatic perception and production must be conceived as a multifaceted phenomenon. Instructors might be encouraged to employ more perception-focused approaches to pragmatic instruction earlier and focus on production activities at later stages of learners' development (Jernigan, 2012).

As the study and research into the area of interlanguage pragmatics in EFL context is somehow young, further investigation is needed to find out the effective ways of teaching pragmatics in EFL context. This study investigated the instruction of speech acts in reading and writing modality. The same study can be conducted in listening modality using audiovisual materials to see to what extent the change of different modalities affects the awareness and production of speech acts. Moreover, the instruments employed in this study were WDCT and MDCT. Research is suggested to be conducted using other instruments such as the Oral Discourse Completion Task (ODCT), the Discourse Role-Play Task (DRPT), and the Discourse Self-Assessment Task (DSAT) to triangulate the data (see Brown, 2001). Also of interest in this regard is how input- and output-based activities may be combined to promote greater pragmatic learning. One question that is worth researching is to examine the learning strategies that are implemented by Persian EFL learners in their acquisition of interlanguage pragmatics.

\section{REFERENCES}

[1] Aljaafreh, A., \& Lantolf, J. P. (1994). Negative feedback as regulation and second language learning in the Zone of Proximal Development. The Modern Language Journal, 78(4), 471-83.

[2] Bardovi-Harlig, K. (2001). Evaluating the empirical evidence of the need for instruction in pragmatics. In K. Rose \& G. Kasper (Eds.), Pragmatics in language teaching (pp. 13-32). Cambridge: Cambridge University Press.

[3] Bardovi-Harlig, K. (2013). Developing L2 pragmatics. Language Learning, 63, 68-86.

[4] Bardovi-Harlig, K., \& Hartford, B. S. (1993). Learning the rules of academic talk: A longitudinal study of pragmatic development. Studies in Second Language Acquisition, 15, 279-304.

[5] Birjandi, P. \& Rezaei, S. (2010). Developing a multiple-choice discourse completion test of interlanguage pragmatics for Iranian EFL learners. ILI Language Teaching Journal (Special Issue: Proceedings of the First Conference on ELT in the Islamic World), 6(1, 2), 43-58.

[6] Donato, R. (1994). Collective scaffolding in second language learning. In J. P. Lantolf \& G. Appel (Eds.), Vygotsian approaches to second language research ( $\mathrm{pp}$. 33-56). Norwood, NJ: Ablex.

[7] Ellis, R. (1997). SLA research and language teaching. Oxford: Oxford University Press.

[8] Eslami-Rasekh, Z. (2005). Raising the pragmatic awareness of language learners. ELT Journal, 59(3), 199-208.

[9] Eslami-Rasekh, Z., Eslami-Rasekh, A., \& Fatahi, A. (2004). Using metapragmatic instruction to improve advanced EFL learners pragmatic awareness. TESL EJ, 8 (2) A2, 1-12. 
[10] Izumi, S. (2002). Output, input enhancement, and the noticing hypothesis: An experimental study on ESL relativization. Studies in Second Language Acquisition, 24, 541-577.

[11] Izumi, S. (2003). Comprehension and production processes in second language learning: In search of the psycholinguistic rationale of the output hypothesis. Applied Linguistics, 24, 168-196.

[12] Jabbarpoor, Sh., \& Tajeddin, Z. (2013). Enhanced input, individual output, and collaborative output: Effects on the acquisiti on of the English subjunctive Mood. Revista Signos, 46(82) 213-235.

[13] Jernigan, J. E. (2007). Instruction and developing second language pragmatic competence. Unpublished doctoral dissertation, The Florida State University. Retrieved October 3, 2012, from http://diginole.lib.fsu.edu/cgi/viewcontent.cgi?article=2565\&context=etd.

[14] Jernigan, J. (2012). Output and English as a second language pragmatic development: The effectiveness of output-focused video-based instruction. English Language Teaching, 5(4), 1-12.

[15] Jianda, L. (2007). Developing a pragmatics test for Chinese EFL learners. Language Testing, 24(3), 391-415.

[16] Kasper, G. (2001a). Classroom research on interlanguage pragmatics. In K. R. Rose \& G. Kasper (Eds.), Pragmatics in language teaching (pp. 33-60). Cambridge: Cambridge University Press.

[17] Kasper, G. (2001b). Four perspectives on L2 pragmatic development. Applied Linguistics, 22(4), 502-530.

[18] Kasper, G., \& Rose, K. R. (2002). Pragmatic development in a second language. Oxford: Blackwell.

[19] Kasper, G., \& Schmidt, R. (1996). Developmental issues in interlanguage pragmatics. Studies in Second Language Acquisition, $18,149-169$.

[20] Khatib, M. \& Ahmadi Safa, M. (2011). The effectiveness of ZPD-wise explicit/implicit expert peers and co-equals scaffolding in ILP development. IJAL, 14(1), 49-76.

[21] Lapkin, S. \& Swain, M. (2000). Task outcomes: A focus on immersion students' use of pronominal verbs in their writing. Canadian Journal of Applied Linguistics, 3, 7-22.

[22] Mackey, A., \& Gass, S. M. (2005). Second language research: Methodology and design. Mahwah, NJ: Lawrence Erlbaum.

[23] Mirzaei, A., \& Esmaeili, M. (2013). The effects of planned instruction on Iranian L2 learners' interlanguage pragmatic development. International Journal of Society, Culture \& Language, 1, 89-100.

[24] Nassaji, H., \& Cumming, A. (2000). What's in a ZPD? A case study of a young ESL student and teacher interacting through dialogue journals. Language teaching Research, 4(2), 95-121.

[25] Nassaji, H., \& \& Swain, M. (2000). A Vygotskian perspective on corrective feedback in L2: The effect of random versus negotiated help on the learning of English articles. Language Awareness, 9(1), 34-51.

[26] Nassaji, H., \& Tian, J. (2010). Collaborative and individual output tasks and their effects on learning English phrasal verbs. Language Teaching Research, 14(4) 397-419.

[27] Ohta, A. S. (1999). Interactional routines and the socialization of interactional style in adult learners of Japanese. Journal of Pragmatics, 31, 1493-1512.

[28] Ohta, A. S. (2001). Second Language Acquisition Processes in the Classroom: Learning Japanese. Mahwah, NJ: Lawrence Erlbaum Associates.

[29] Ohta, A. S. (2005). Interlanguage pragmatics in the zone of proximal development. System, 33, 503-517.

[30] Olshtain, E., \& Cohen, A. (1990). The learning of complex speech act behavior. TESL Canada Journal, 7, 45-65.

[31] Rose, K. R. (2005). On the effect of instruction in second language pragmatics. System, 33(3), 385-399.

[32] Safont, M. P. (2005). Third language learners. Pragmatic production and awareness. Clevedon: Multilingual Matters.

[33] Schauer, G. A. (2009). Interlanguage pragmatic development: The study abroad context. London: Continuum.

[34] Schmidt, R. (1993). Consciousness, learning and interlanguage pragmatics. In G. Kasper \& S. Blum-Kulka (Eds.), Interlanguage pragmatics (pp. 21-42). Oxford: Oxford University Press.

[35] Schmidt, R. (1995). Consciousness and foreign language learning: A tutorial on the role of attention and awareness. In R. Schmidt (Ed.), Attention and awareness in foreign language teaching and learning (Technical Report No. 9) (pp. 1-63). Honolulu: University of Hawai'i at Manoa.

[36] Schmidt, R. (2001). Attention. In P. Robinson (Ed.), Cognition and second language instruction (pp. 3-33). New York: Cambridge University Press.

[37] Sharwood Smith, M. (1981).Consciousness-raising and the second language learner. Applied Linguistics, 11, 159-168.

[38] Sharwood Smith, M. (1991). Speaking to many minds: On the relevance of different kinds of language information for the L2 learner. Second Language Research, 7, pp.118-132.

[39] Sharwood Smith, M. (1993). Input enhancement in instructed second language acquisition: Theoretical bases. Studies in Second Language Acquisition, 15, 165-180.

[40] Storch, N. (1997). The editing talk of adult ESL learners. Language Awareness, 6, 221-32.

[41] Storch, N. (2005). Collaborative writing: Product, process, and students' reflections. Journal of Second Language Writing, 14, 153-73.

[42] Swain, M. (1985). Communicative competence: Some roles of comprehensible input and comprehensible output in its development. In S. Gass \& C. Madden (Eds.), Input and second language acquisition (pp. 235-253). Rowley, MA: Newbury House.

[43] Swain, M. (1995). Three functions of output in second language learning. In G. Cook \& B. Seidhofer (Eds.) Principles and practice in applied linguistics (pp. 125-144). Oxford: Oxford University Press.

[44] Swain, M. (1998). Focus on form through conscious reflection. In C. Doughty \& J. Williams (Eds.), Focus on form in classroom second language acquisition (pp. 64-81). New York: Cambridge University Press.

[45] Swain, M. (2005). The output hypothesis: Theory and research. In E. Hinkel (Ed.), Handbook of research in second language teaching and learning (pp. 471-484). Mahwah, NJ: Lawrence Erlbaum Associates.

[46] Swain, M., \& Lapkin, S. (2002). Talking it through: Two French immersion learners' response to reformulation. International Journal of Educational Research, 37, 285-304.

[47] Taguchi, N. (2007). Task difficulty in oral speech act production. Applied Linguistics, 28, 113-135. 
[48] Taguchi, N. (2009). Comprehension of indirect opinions and refusals in L2 Japanese. In N. Taguchi (Ed.), Pragmatic competence (pp. 249-274). New York: Mouton de Gruyter.

[49] Takahashi, S. (1996). Pragmatic transferability. Studies in Second Language Acquisition, 18, 189-223.

[50] Takahashi, S. (2001).The role of input enhancement in developing pragmatic competence. In K. R. Rose \& G. Kasper (Eds.), Pragmatics in language teaching (pp. 171-199). Cambridge: Cambridge University Press.

[51] Takimoto, M. (2006). The effects of explicit feedback and form-meaning processing on the development of pragmatic proficiency in consciousness-raising tasks. System, 34, 601-614

[52] Takimoto, M. (2007). The effects of input-based tasks on the development of learners' pragmatic proficiency. Applied Linguistics, 30(1), 1-25.

[53] Takimoto, M. (2008). The effects of various kinds of form-focused instruction on learners' ability to comprehend and produce polite requests in English. TESL Canada Journal, 26(1), 31-51.

[54] Takimoto, M. (2009). Exploring the effects of input-based treatment and test on the development of learners' pragmatic proficiency. Journal of Pragmatics, 41, 1029-1046.

[55] VanPatten, B., \& Cadierno, T. (1993). Explicit instruction and input processing. Studies in Second Language Acquisition, 15, 225-243.

[56] Vygotsky, L. S. (1978). Mind in society: The development of higher psychological processes. Cambridge, MA: Harvard University Press.

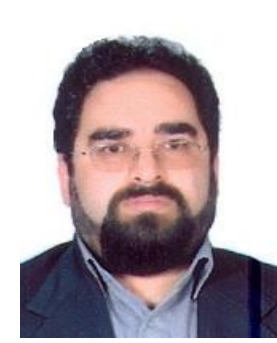

Majid Nemati received his PhD in applied Linguistics from Leicester University, Great Britain in 2000. He is currently an Assistant Professor at the University of Tehran where he is the head of the English Language and Literature Department. His area of interest includes applied linguistics, writing, ESP and first language acquisition. He has published a number of articles both in national and international journals and has given lectures in a number of local and international conferences. Besides, Dr Nemati has written and translated some books.

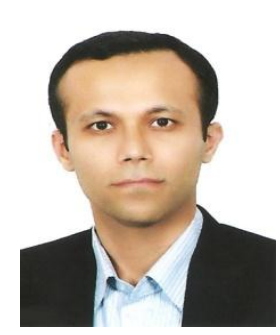

Ali Arabmofrad was born in Gorgan, Iran, in June 1980. He finished his BA in English Translation at the University of Chabahar, Iran, in 2001. He did his MA at the University of Tehran (UT), Iran, in 2004, in the field of TEFL. At the moment, he is a PhD candidate at UT in TEFL. Starting from 2008, he is currently a Lecturer at the Golestan University and Islamic Azad University of Gorgan. His main research interest is psycholinguistics and pragmatics. 